\title{
Discussion on the Teaching Mode of Applied Development Courses under Emerging Engineering Education
}

\author{
Yu Luo ${ }^{1}$ \\ Department of Mechanical Engineering \\ GuiZhou University \\ Guiyang, China
}

\author{
Yanlei $\mathrm{Luo}^{2} *$ Corresponding Author \\ Department of Mechanical Engineering \\ GuiZhou University \\ Guiyang, China
}

\author{
Chuanbao Guan ${ }^{3}$ \\ Department of Mechanical Engineering \\ GuiZhou University \\ Guiyang, China
}

\begin{abstract}
The Applied Development Courses refer to those courses that emphasize hands-on skills. In the current Emerging Engineering Education, these courses aim to develop complex engineering practical system. It is very difficult to transfer knowledge to skill in a short period by purely depending on lecture and experiment. A novel teaching mode is proposed in order to balance the contradiction between the reduction of teaching hour and the improvement of teaching requirements. This mode adds project driven task based on te am collaborative learning to the current teaching mode. We put forward a series of solutions to process supervising, individual assessment in te am and after-class tutorial . In the execution of this teaching mode, the students' team cooperation ability, system developing skills and project recommendation ability are cultivated. This mode breaks up the traditional mode as teacher's unilateral teaching and students' passive learning.
\end{abstract}

Keywords-Emerging Engineering Education; project driven teaching; Applied Development Courses; teaching mode; collaborative learning

\section{INTRODUCTION}

China signs Washington Accord at the meeting of the International Engineering Alliance held in June, 2016 ${ }^{[1]}$, which stimulates an innovation at the engineer cultivation in China. A concept, Emerging Engineering Education, is proposed to adapt the innovation ${ }^{[2][3]}$. The cultivation of student engineers in Emerging Engineering Education bases on the solving of huge complex engineering problems. And the educational concept of the education focuses on the skill cultivation.

Under the orientation and target of Emerging Engineering Education, the importance of Applied Development Courses in Engineering is becoming increasingly prominent. The Applied Development Courses include Numerical Control, Single-Chip Microcomputer, Programmable Logic Controller,

Sponsor: Major Research Project of innovative Group by Guizhou Education Department (Qianjiao he KY [2017] 029); Undergraduate

Teaching Engineering Construction Project of Guizhou

University(JG201718)
Programming in C, Sensor Technology, etc. These courses are the critical technology widely applied in engineering practice. The education emphasizes hands-on developing skill.

The Emerging Engineering Education requires the capability to develop system skill and increase engineering practice. With the improvement of internet and AI, the main trend mode of engineer education is changing ${ }^{[4]}$. The education time of Applied Development Courses decreases in undergraduate engineering education stage. We should converse from professional knowledge to skill in a limited class time, and improve the teaching mode.

In view of these contradictions, this paper proposes a teaching mode. By improving and extending teaching methods, the traditional education of knowledge and skills is changed into project-driven task training. Through the innovation of teaching mode, students' cooperation ability, technical practical skill and communication ability have improved to meet the requirements of Emerging Engineering Education.

\section{THE STATUS QUO OF APPLIED DEVELOPMENT COURSES IN ENGINEERING EDUCATION}

In the current higher education, many colleges and universities pay more attention to improve the students' overall quality. The course aimed to elevate the student's appreciative and creative quality increases hour proportion, while the course hour of the engineering Applied Development is compressed. It puts forward a new challenge to the teaching design of engineering Applied Development Course. How to cultivate the students' skill through limited class hours? How to promote the conversion of knowledge to practical skill? The traditional curriculum assignment and practical training have the following disadvantages when they face challenges.

1) The teaching emphasis is limited to imparting knowledge. The classroom teaching of Applied Development 
Courses mainly bases on knowledge points. The unique manipulating opportunity comes from the matching experiment curriculum. But the experiment hour is short, and the main parts are verifications. Without the comparing practical training, the students have no time to ask questions and their system developing skill can't elevate.

2) The exam assessment lacks the evaluation of students' practical application skill. The form of current examination is mainly paper test. The students focus on the knowledge memory, which can't be transformed to skills in engineering.

3) Lack of supervision mechanism in after-class study. The teaching assignment lacks the guidance and assessment of after-class practice. There is no incentive mechanism to encourage the students to involve in the after-class practice study. So the students learning activities are limited in the Teacher's unilateral teaching.

4) The content of classroom is out of step with engineering practical application. There is a long distance between the Applied Development Courses knowledge and the technical application. If the students want to take part in the competition or the Student Research \& Technology Project, they have to spend a lot of time selecting components, designing electronic circuits, and programming, etc. These restrict the creativity level and competitive edge of their fruits. And many subsystems developed in the Applied Development Courses can be reused in a complex engineering system.
The above problems have been reflected in Chinese engineers who are newly graduated from colleges and universities. A survey conducted by the Ministry of Education on the satisfaction of engineers by relevant industry organizations and employers shows that the engineering core competence of Chinese engineering graduates can't satisfy the requirements ${ }^{[5]}$. According to the Quality of Chinese Engineering Education Report, the results of investigation on supporting degree of the conditions of running an education shows that only $40 \%$ of the professional course system support is in good condition. The $50 \%$ cultivating goal of the professional course system in support of continuity and stability still needs to be paid attention to. The $10 \%$ system exists obvious problems in the professional curriculum system $^{[5]}$. Insufficient participation of industry and employers in the curriculum weakens the training of comprehensive engineering skill.

\section{THE TEACHING ORGANIZATION FORM OF APPLIED DEVELOPMENT COURSE}

The teaching mode gears to the Emerging Engineering Education and the guiding ideology of this mode is teaching process modular, teaching design project-driven, team organization flexible and learning evaluation comprehensive. The teaching process is shown in Fig.1. The whole teaching organization highlights the following characteristics.

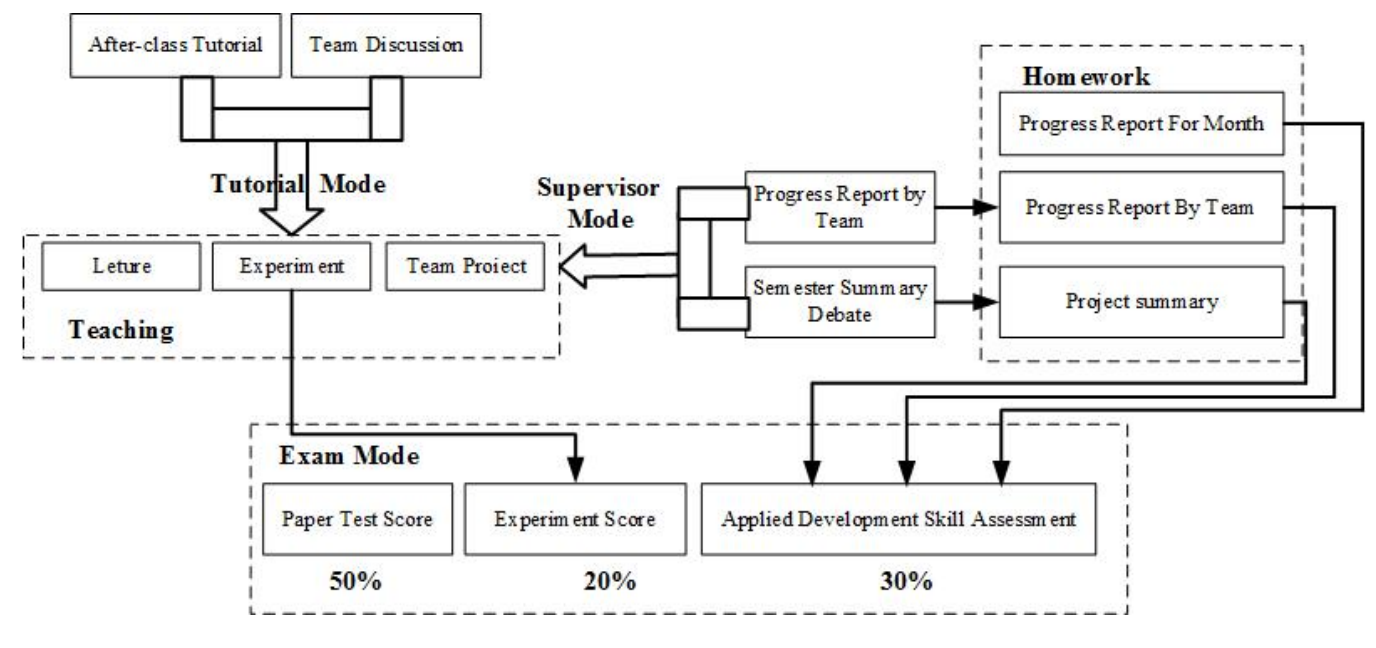

Fig. 1. Teaching Organization

\section{A. Flexibility based on modular course design}

The teaching process is divided into three modulesLecture, experiment and team project. Lecture and experiment modules use traditional teaching mode. Team project is an innovation.

In terms of teaching objectives, it not only passes on the existing knowledge and skills, but also is close to the future engineering application scenarios. So the teaching mode can cultivate students' ability of independent research, teamwork and problem solving. As to the teaching organization, the maximum integration of classroom learning and after-class practice training hour can be achieved through the flexible construction of each module. 


\section{B. Initiative and skill cultivation based on task-driven and project-driven teaching design}

In the study of task design, the students abandon passive acceptance and knowledge memory. They realize the study objectives through active research and learning. At the beginning of a curriculum, the teacher publishes all projects of system development about this course, which are company with references. The students choose one project after assembling teams freely and the process of project developing of every team is supervised through Progress Report by Team and Semester Summary Debate.

In the design of teaching content, besides covering the necessary professional knowledge points, the project topic is involved in engineering practicability. One team is in charge of one project, which is composed of 5-7 persons. The tasks of each team include planning, division of labour, implementation, project progress report, project development log, results summary, etc. The project periodic result exhibitions of every team are held irregularly. At the end of the semester, a publication of the final results and Summary Debate will be celebrated.

In the topic selection of the team practical project, it can be oriented from the various discipline competitions, or from engineering practice. The teacher simplifies the subject from the actual engineering, so that the difficulty of the design project spirals up. The team members can achieve it by consulting materials, guiding by teachers or consultants, and thinking autonomously. Reasonable project topic selection can encourage students' interest in learning, which is the motivation to stimulate students' initiative, thirst for knowledge and enthusiasm for learning ${ }^{[6]}$.

\section{Cooperation cultivation based on team learning}

Engineering education is bound to serve the industry practice in the future. The student engineers will be involved in teamwork in the future during production and research practice.

During the teaching mode proposed in this paper, every member of the team plays a role in the project processing, such as leader, reference searcher, electric circuit planner, programmer, project presenter. And there exists a periodic rotation. No one could wait for others' help.

Team collaborative learning transforms students' individual knowledge learning into team cooperative research learning, which is more in line with the rules of learning in the knowledge explosion and AI era. The student engineers' team cooperation, communication and team competition ability are cultivated in the form of manufacturing of modern industry and scientific research practice.

\section{Objective and comprehensive assessment based on team report and practices skill}

According to this new teaching organization scheme, the evaluation of students takes into account of the mastery of professional knowledge and the practical developing skill gained from engineering practice. The three assessment indices are final Paper Test Score, Experimental Score and Applied Development Skill.
Among them, the score of Applied Development Skill is different from the objective score system of the Paper Test, which is subjective and hard to come up with a uniform standard. It is especially important to establish a set of assessment standard that matches the teaching mode. In order to avoid the one-sidedness of grading, the result of the grading affirmes the students' paying and effort based on the aforementioned teaching design. After careful consideration, we choose three indices as the assessment, namely Participation in Project Development, Project Reporting and Defense Ability.

The Participation in Project Development reflects whether a member has involved in the project process, and whether the amount of his labour is sufficient. The Project Reporting reflects whether the team execution is in accordance with their plan. This index can be graded by the Progress Report for Month and Team Discussion Note. The Defense Ability reflects the team member' advertise ability. They not only introduce their project and fruits, but also answer other people's questions. In order to improve the student engineers' express and debate skills, the questioner can tutor members of other teams. A creative question can give extra scores to the student questioner.

All the indices give a combination assessment to student engineer with factors.

$$
F S=T P S \times 0.5+E X P S \times 0.2+A D S A \times 0.3
$$

Where FS is Final Score,

TPS is Test Paper Score,

EXPS is Experimental Score,

ADSA is Applied Development Skill Assessment, which can be evaluated by Equation (2).

$A D S A=(P R M \times a \%+P R T \times b \%+P S \times c \%) \times P P D$

where $P R M$ is Progress Report for month

\section{$P R T$ is Progress Report by Team}

\section{$P S$ is Project Summary}

PPD represents Participation in Project Development, the average value of which is 1 . If one member has an excellent performance in the project, he can get more than 1 value of PPD. Less than 1 value of PPD means less labour in the project developing.

\section{Conclusion}

The new technology has brought about innovation to teaching and learning. The future complex engineering problems faced by Emerging Engineering Education engineers are random, unstructured, variable and cross-disciplinary ${ }^{[7][8]}$.Design and applied de velopment skill is more important than knowledge points especially in Applied Development Course. The traditional teaching mode, like teacher's unilateral teaching and students' passive acceptance, can't meet the requirements of the Emerging Engineering Education. 
In order to verify the teaching effect, the teaching mode proposed here is carried out in the curriculum of Single Chip Microcomputer Development. The applied development projects are designed to train the teams, including stepper motor driven and control, color sensor sample and display, electrical clock, feedback control based on temperature sensor, supersonic ranging and control, etc. The proportion of the independent accomplishment of the project is 68\% and the proportion of the project accomplishment assisted by the consultant is about $22 \%$. The teachers need to pay attention to the rest teams, the proportion of which is about $10 \%$. Because students have difficulty in conducting the process by themselves, teachers should give them more guidance and help. The universal difficulty of Applied Developing Course is programming. As statistics are shown, three quarter of the developing time is spent on debugging. Some project fruits are shown in Fig.2 and Fig.3.

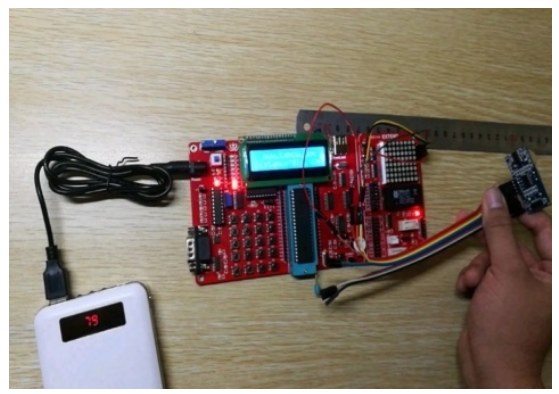

Fig. 2. Ultrasonic ranging and control

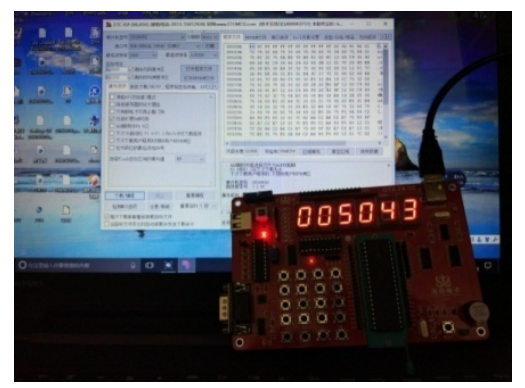

Fig. 3. Electrical clock

Students take the initiative to learn with tasks, by which they can enhance their interest in learning and cultivate their ability to ask questions and innovate. Several phenomena have been observed:

1) The students are more likely to ask questions, not only to the tutor, but also to everyone else even in the report and debate.

2) The conversion from professional knowledge to skill outside the classroom is achieved. When the team gets stuck, they will discuss mutually. Sometime they will call for help from tutor by team cell.

3) More and more student would like to share their experience in front of the platform. Through times of discussion and report, the students build their confidence.

\section{ACKNOWLEDGMENT}

Thanks to the sponsor Major Research Project of innovative Group by Guizhou Education Department (Qianjiao he KY [2017] 029), and Undergraduate Teaching Engineering Construction Project of Guizhou University (JG201718), the teaching mode innovation has carried out.

\section{REFERENCES}

[1] Hua Ertian, Ji Weirong, Wu Xiangming.“Exploration and Practice of Engineering Innovative Talents Cultivation Based on the Background of China Signing Washington Accord”. China Higher Education Research, pp. 82-85, January 2017. (In Chinese)

[2] JianWen Guo, XiaoChang Cao, Li Xie, et.al. "Development of engineering drawing ability for emerging engineering education”. IOP Conference Series: Materials Science and Engineering, pp. 1-4, 2017

[3] Yang Ruofan, He Qian.“ABET Criteria for Engineering Technology Programs and its Enlightenment for the Establishment of Colleges and Universities of Applied Science in China”. China Higher Education Research, pp, 87-91,106, August 2015.(In Chinese)

[4] Patric Willin, Tom Adawi, Julie Gold. "Linking teaching and research in an undergraduate course and exploring student learning experiences”, European Journal of Engineering Education.Vol.42, pp. 58-74, 2017

[5] Georgia Institute of Technology Complete College Georgia Plan 2016 Status Report October 28, 2016.

[6] Borrego Maura, Bemhard Jonte.”The Emergence of Engineering Education Research as a Globally Connected Field of Inquiry”. Journal of Engineering Education, Vol.100, pp. 14-47, 2011.

[7] Lin Jian. "Cultivating the Competence of Solving Complex Engineering Problems by Using PBL”. Research in Higher Education of Engineering, pp.79-89, February 2017. (In Chinese)

[8] Lin Jian. “On Outstanding Engineers' Innovation Ability Training”, Research in Higher Education of Engineering, pp.1-17, May 2012. (In Chinese) 